\title{
The Effect of Heating Temperature on Static Hardness of Beech (Fagus Sylvatica L.) Wood
}

\author{
Arian Kapidani ${ }^{+*}$, Dritan Ajdinaj (Hajdini) ${ }^{\dagger}$ and Saimir Beqo ${ }^{\dagger}$ \\ †Department of Wood Industry, Agricultural University of Tirana, Kodër-Kamëz, Tirana, Albania \\ Received 01 March 2019, Accepted 01 May 2019, Available online 02 May 2019, Vol.9, No.3 (May/June 2019)
}

\begin{abstract}
A study was carried out to evaluate the effects of heating treatment on static hardness of beech (Fagus sylvatica L.) wood of Albanian origin. The heat treatment was conducted at temperatures 180, 200 and $220^{\circ} \mathrm{C}$ for 2 hours, at atmospheric pressure. Samples were produced from logs sapwood of origin from central Albania. Before treatment the oven dried density was calculated. The weight loss after treatment resulted from the lowest to the highest temperature respectively 3.57, 5.33 and 9.46\%. It was noted a small decrease of hardness for temperatures up to $200^{\circ} \mathrm{C}$, while for higher temperature the hardness decreased considerably, up to 20\%. Decrease of hardness in tangential section was lower than in radial one. From the perspective of utilisation it seems that Albanian beech wood treated at temperatures up to $200^{\circ} \mathrm{C}$ presents a suitable choice for indoor and outdoor stairs, floor tiles and parquet.
\end{abstract}

Keywords: wood, beech, heat, treatment, hardness

\section{Introduction}

Thermal treatment aims at improving the performance of wood during its use in certain conditions. It has been recognized decades ago as useful modify method to improve the dimensional stability of wood and its decay resistance (Kollman, et al, 1975). Thanks to its eco-friendly approach, it is nowadays the most advanced commercially method (Hill, 2006). During last two decades several industrial application are developed in Europe, such as Thermowood in Finland, Rectification and Bois Perdure in France, Platowood in Netherland, Oil-heat treated wood in Germany and Thermo-vacuum wood in Italy. The main differences between these applications are in treatment conditions, such as use of steam or water spray or oils, application of oxygen or nitrogen or vacuum, as well as different treatment stages (Militz, 2002; Ferrari, et al, 2012). Anyway, heat treatment has positive impact mainly on physical properties of wood and its biological durability, while on mechanical ones negative consequences are evident (Epmeier, et al, 2003; Esteves and Pereira, 2009; Unsal, et al, 2009). From the perspective of wood utilization this fact means that for proper performance during application, the limiting conditions have to be taken into account.

Because of high temperature during heat treatment the wood chemical structure is modified, causing

*Corresponding author's ORCID ID: 0000-0002-9014-9057 DOI: https://doi.org/10.14741/ijcet/v.9.3.3 permanently changes of its properties. Changes start appears at about $150^{\circ} \mathrm{C}$ and become more evident as the temperature becomes higher (Hill, 2006). Hemicellulose, which constitutes $25-35 \%$ of wood, has high oxygen content and degrades faster than cellulose and lignin and at lower temperatures (Fengel and Wegener, 1984; Esteves and Pereira, 2009). During this process methanol, acetic acid and various volatile heterocyclic compounds are produced. The exact temperature for the onset of hemicelluloses degradation varies on the mode of treatment and ranges from $90-150^{\circ} \mathrm{C}$. When steam is used acetic acid starts to be formed from hemicelluloses at $120^{\circ} \mathrm{C}$, by hydrolysis.

This acid serves as catalyst in the hydrolysis of hemicelluloses to soluble sugars, causing a reduction of hemicelluloses amount in wood. With degrading of the hemicelluloses, the concentration of water-absorbing hydroxyl groups decreases. As consequence, the equilibrium moisture is reduced; dimensional stability, biological durability and weather resistance are improved (Kotilainen, 2000). By the other hand cellulose which constitutes $40-50 \%$ of wood consists in chains joined by bonds between hydroxyl groups. At high temperatures cellulose starts decomposition, eliminating water and increasing crystallinity as well as dimensions of crystals. As consequence, the equilibrium moisture content is reduced and the toughness of wood is changed. Lignin varies from 20 $30 \%$ of wood and has the best ability to withstand heat. 
Lignin's mass start to decrease above $200^{\circ} \mathrm{C}$, because of its chemical bonds start to break. The assessment of lignin content in wood was based on valuation of nonhydrolysable residues (Hill, 2006). It affects biological durability, strength and paintability of heat treated wood (FTA, 2003).

There are several variables which effect on heat treatment, such as time and temperature of treatment (Esteves and Pereira, 2009), wood species (Militz, 2002; Ibach, 2010), treatment atmosphere and sample dimensions (Hill, 2006), initial moisture content (Gaff and Gasparik, 2013), maturity of wood (Bal and Bektas, 2012; 2013), use of catalysts (Fengel and Wegener, 1989) as well as wet and dry systems (Burmester, 1981).

Beech (Fagus sylvatica L.) is one of the most important European hardwoods. In Albania it occupies around $60 \%$ of total forests volume and is used for tiles and parquet, desks and chairs, solid wood panels, doors, stairs etc. It has high density and presents good physical and mechanical properties, but his biological durability leaves much to be desired. Improvement of its properties always has been a primary interest.

Czech researchers studied the impact of heat treatment on the elastic and strength properties of European beech (Fagus sylvatica L.) applying two different values of temperature, 165 and $210^{\circ} \mathrm{C}$. They improvised based on the Finish technology, using sprinkling instead of steam. It was found that impact toughness of wood treated in $210^{\circ} \mathrm{C}$ was decreased by about 81\%, meanwhile the static bending strength decreased 59\%. Higher temperatures of heat treatment correlated with lower elastic and strength properties (Boruvka, et al, 2018).

A study was carried out to analyse the effect of heat treatment under atmospheric pressure on some of physical and mechanical properties of Turkish beech (Fagus orientalis Lipsky). Samples were treated at $150^{\circ} \mathrm{C}, 175^{\circ} \mathrm{C}$ and $200^{\circ} \mathrm{C}$ for 1,3 and 5 hours. The results showed an increase of weight loss, density loss and dimensional stabilization. Also, the compression strength parallel to grain was increased, except for the treatment at $200^{\circ} \mathrm{C}$ for 5 hours. It was noted that treatments no longer than 3 hours, at low temperature, did not influence negatively on mechanical strength, meanwhile higher temperatures and duration decreased noticeably wood strength (Percin, et al, 2016).

Regarding to the heat treatment, a study was carried out to evaluate the influence of heat temperature on static hardness of European beech (Fagus sylvatica L.) of Albanian origin. The results should give suitable information regarding to utilization of heat treated beech for a proper application as tiles and parquet.

\section{Materials and method}

The study was based on comparative laboratory method, cause-consequence. Method consists in quantity evaluation of a specific phenomena caused by a provocative factor and after, in evaluation of the same phenomena in situation of the factor's absence. In our case, the phenomenon is Brinell hardness and the provocative factor is heating temperature.

Laboratory tests consisted in preparation of samples, treatment (heating), weighing of samples and measurements of their dimensions, tests of hardness. The study was carried out at the Faculty of Forestry Sciences of Tirana, during the period February 2019.

As raw material for production of samples were used air dried beech boards (Fagus sylvatica L.), selected randomly at lumberyard of SINANI sawmill. Boards were produced from logs harvested by sawmill itself from forests of Librazhdi region, central Albania. From selected boards were obtained pieces which presented neither deformations nor wood structure defects. Taking into account the presence of red heart in beech wood, the pieces were selected from sapwood zone.

From each piece was saw one strip with dimensions of section $55 \times 55 \mathrm{~mm}$, and length the same as the piece. After, the strips were planed up to the section's dimensions $50 \times 50 \mathrm{~mm}$ and were cut in samples with dimensions 50x50x50 mm. Samples presented clear radial, tangential and cross-sections. There were produced 64 samples in total, which were assigned to 4 different test groups. Group 1 with only 8 samples was used as the control group. The other three groups consisted of 18 samples each.

Before treatments all samples were dried at $103 \pm 2{ }^{\circ} \mathrm{C}$ until to the moisture content $0 \%$. After that the oven dried samples were measured by digital calliper (accuracy $0.001 \mathrm{~mm}$ ) and weighted by digital weight scale (accuracy $0.01 \mathrm{~g}$ ), in order to calculate the respective density. Heat treatments were conducted in small temperature controlled chamber (France Etuves, FRANCE). There were used three different temperatures, 180,200 and $220{ }^{\circ} \mathrm{C}$ at atmospheric pressure for 2 hours.

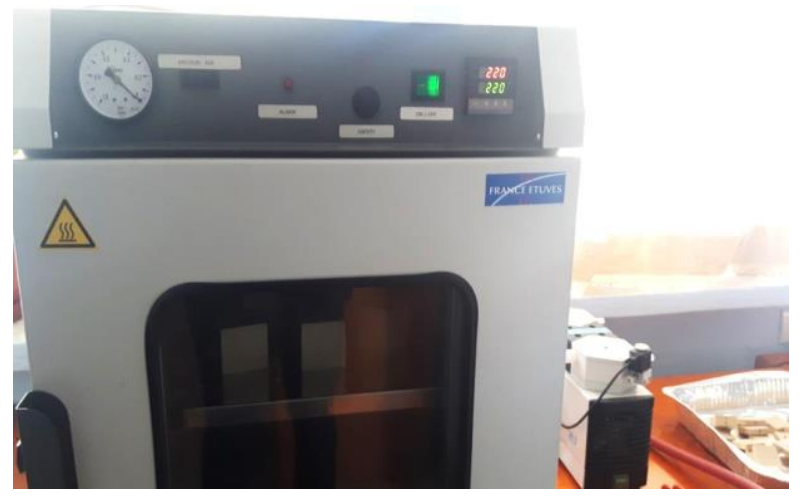

Fig.1 Thermal chamber used for the treatment

After treatment, the samples were weighted again and the weight loss (WL) was calculated by formula:

$W L=\frac{W_{B T}-W_{A T}}{W_{B T}} \times 100 \quad[\%]$ 
where:

$W_{B T}$-the weight of oven dried samples before treatment $(\mathrm{g}) ; W_{A T}$-the weight of samples after heat treatment.

Treated and untreated samples were conditioned until when the moisture content of untreated samples arrived to $12 \%$. Then, the samples were tested on a 20 $\mathrm{kN}$ universal mechanical testing machine (Controlab, FRANCE) to evaluate the Brinell hardness (HB) respectively to radial and tangential sections, applying the load $2800 \mathrm{~N}$. The hardness was calculated by formula:

$$
H B=\frac{2 \times F}{\pi \times D \times\left(D-\sqrt{D^{2}-d^{2}}\right)} \quad\left[\mathrm{N} / \mathrm{mm}^{2}\right]
$$

where: $\quad F-$ the load applied (N);

$D$ - diameter of the steel ball ( $\mathrm{mm})$;

$d$ - diameter of indentation made by steel ball on the surface of the test sample ( $\mathrm{mm})$.

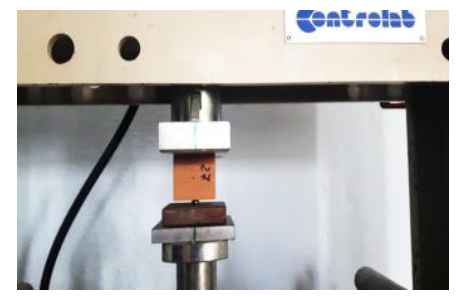

Fig.2 Testing machine

\section{Results and discussion}

A darkness of samples color was observed after treatment. The darkness was intensified for higher heating temperatures. This is a well-known phenomenon. The color is affected by the temperature and the time of treatment. It also depends on whether springwood or latewood is used (FTA, 2003). Studies showed that heat treated beech has darker color to radial and tangential sections. The color difference in its surface decreased depending on treatment intensity, meanwhile the color saturation decreased proportionally to treatment severity (Mitani and Barboutis, 2014). The color can be used to estimate the brittleness of heat treated wood as well as an indicator of the process conditions (Phuong, et al, 2007; Guller, 2012).

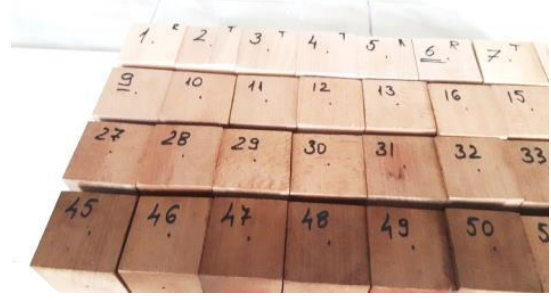

Fig.3 Increase of darkness for treated samples
In table 1 are presented summarised results of oven dried density (D), weight loss (WL) and Brinell hardness referring to radial (HBR) and tangential (HBT) sections for 4 groups of samples.

Table 1 Test results

\begin{tabular}{|c|c|c|c|c|c|}
\hline $\begin{array}{l}\vec{D} \\
0 \\
0 \\
0 \\
0 \\
0\end{array}$ & 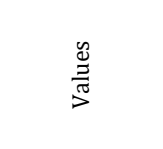 & 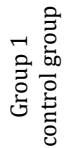 & 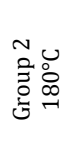 & 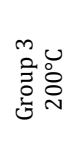 & 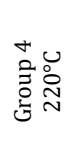 \\
\hline \multirow{3}{*}{ D } & Mean $\mathrm{g} / \mathrm{cm}^{3}$ & 0.68 & 0.668 & 0.671 & 0.68 \\
\hline & Std.Dev. & 0.029 & 0.03 & 0.024 & 0.03 \\
\hline & Coef.Var. \% & 0.043 & 0.045 & 0.036 & 0.044 \\
\hline \multirow{3}{*}{ WL } & Mean $\%$ & - & 3.57 & 5.33 & 9.46 \\
\hline & Std.Dev. & - & 0.54 & 0.59 & 0.46 \\
\hline & Coef.Var. \% & - & 0.15 & 0.11 & 0.05 \\
\hline \multirow{3}{*}{$\begin{array}{c}\mathrm{HB} \\
\mathrm{R}\end{array}$} & Mean N/mm² & 51.03 & 49.39 & 48.39 & 40.81 \\
\hline & Std.Dev. & 4.47 & 5.12 & 5.6 & 4.11 \\
\hline & Coef.Var. \% & 0.09 & 0.1 & 0.12 & 0.1 \\
\hline \multirow{3}{*}{$\begin{array}{l}\mathrm{HB} \\
\mathrm{T}\end{array}$} & Mean $\mathrm{N} / \mathrm{mm}^{2}$ & 50.02 & 49.4 & 49.12 & 42.22 \\
\hline & Std.Dev. & 3.64 & 2.73 & 4.29 & 7.84 \\
\hline & Coef.Var. \% & 0.07 & 0.06 & 0.09 & 0.19 \\
\hline
\end{tabular}

Group 1 was not treated and served to compare the effects of heat treatments on other three groups. The results showed that all three treated groups were affected by heating temperature. The effects were more visible as the temperature was higher. The weight loss for temperatures 180, 200 and $220{ }^{\circ} \mathrm{C}$ were respectively $3.57,5.33$ and $9.46 \%$. It was noted from 200 to $220{ }^{\circ} \mathrm{C}$ the weight decreased more rapidly. Similar results have been reported by other previous studies (Bal, 2015). A strong correlation existed between temperature and weight loss with a coefficient value of 0.974 . The figure 4 shows the relation between heating temperature and weight loss.

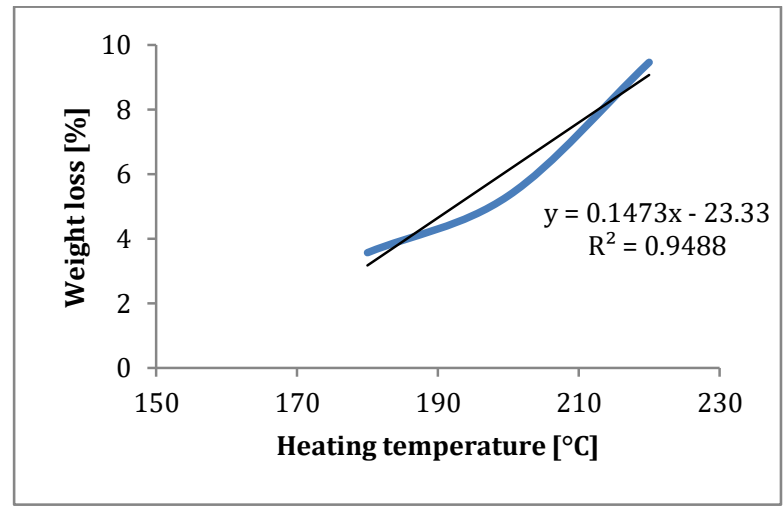

Fig.4 Relation between heating temperature and weight loss

With regard to Brinell hardness it was noted for temperatures 180 and $200{ }^{\circ} \mathrm{C}$ the reductions were not considerable for both sections, meanwhile for temperature $220{ }^{\circ} \mathrm{C}$ the hardness presented a strong decrease. Figure 5 shows the decrease in percentage of Brinell hardness for two directions regarding to heating temperatures. 


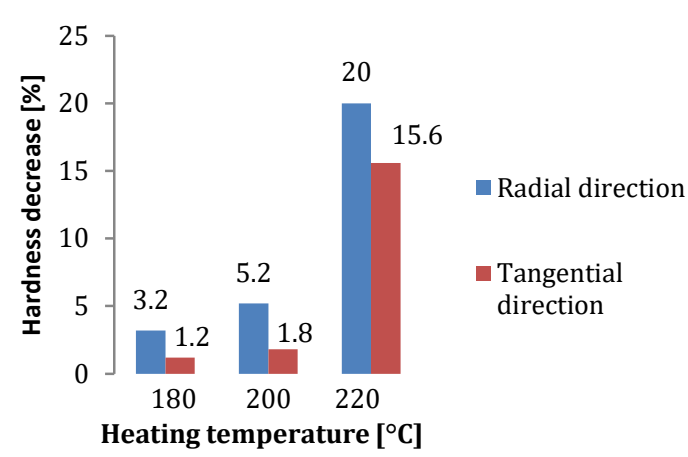

Fig.5 The decrease in percentage of Brinell hardness

The reductions of hardness in tangential section were lower than those in radial section, especially for temperatures 180 and $200^{\circ} \mathrm{C}$. For these temperatures the decrease in radial section is more than double of radial one. Several studies have shown different effects on static hardness of beech. Some of them showed at temperature $165^{\circ} \mathrm{C}$ the hardness of beech (Fagus sylvatica L.) wood was decreased with $2 \%$ in radial section, while for tangential section it was increased with $3 \%$. Respectively, at temperature $210^{\circ} \mathrm{C}$ the hardness was decreased with 37 and 24\% (Boruvka, et al, 2018). By the other hand, studies regarding to Turkish beech (Fagus orientalis Lipsky) showed higher hardness decrease in tangential section than radial one (Percin, et al, 2016). However, both studies mentioned above showed clearly decrease of static hardness of beech wood at higher temperatures.

According to obtained results was noted a strong correlation between weight loss and hardness decrease. This, because of both parameters depends mainly on the depolymerisation reactions of wood polymers, which means degradation mainly of hemicelluloses, followed by more heat resistant celluloses as well as lignin. The degradation develops more intensively at higher temperatures (Kotilainen, 2000). Figure 6 shows the relation between weight loss and hardness decrease during heat treatment.

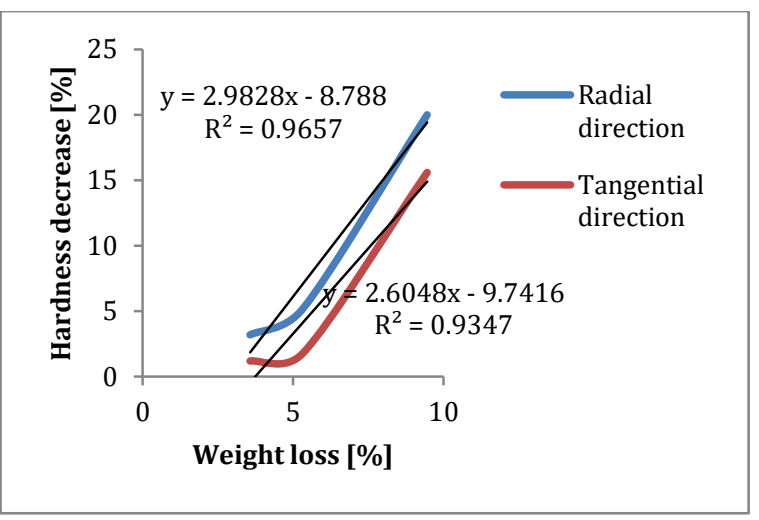

Fig.6 Relation between weight loss and hardness decrease during heat treatment

\section{Conclusions}

Regarding to static hardness it seems that Albanian beech wood presents relatively strong resistance against heating treatment up to $200^{\circ} \mathrm{C}$ at atmospheric pressure. Above this temperature its hardness decreases rapidly up to $20 \%$. Decrease of hardness in tangential section is lower than in radial one. There is a strong positive relation between weight loss and hardness decrease.

Taking into account positive effects of heat treatment on physical properties of wood as well as the reacting of Albanian beech hardness towards heating treatment it seems that a positive perspective does exist for utilisation of heated beech for a proper indoor and outdoor application as stairs, floor tiles and parquet.

\section{References}

A.Burmester, (1981) Dimensional stabilization of wood, Holz als Roh und Werkstoff 33(9), pp.333-335.

A.Mitani, I.Barboutis, (2014) Changes caused by heat treatment in color and dimensional stability of beec (Fagus sylvatica L.) wood, Drvna Industrija 65(3), pp.225-232.

B.C.Bal, (2015) Physical properties of beech wood thermally modified in hot oil and in hot air at various temperatures, Maderas. Cienca y Tecnologia 17(4), pp.789-798.

B.C.Bal, I.Bektas, (2012) The effects of heat treatment on the physical properties of juvenile wood and mature wood of Ecualyptus grandis, BioResources 7(4), pp.5117-5127.

B.C.Bal, I.Bektas, (2013) The effects of heat treatment on some mechanical properties of juvenile wood and mature wood of Ecualyptus grandis, Drying Technology 31(4), pp.479-485.

B.Guller, (2012) Effect of heat treatment on density, dimensional stability and color of Pinus nigra, African Journal of Biotechnology 11(9), pp.2204-2209.

B.M.Esteves, H.M.Pereira, (2009) Heat treatment of wood, BioResources 4(1), pp.370-404.

C.Hill, (2006) Wood Modification: Chemical, Thermal and Other Processes, John Wiley \& Sons, London.

D.Fengel, G.Wegener, (1984) Wood, chemistry, ultrastructure, reactions, Walter de Gruyter \& Co, Berlin.

F.F.P.Kollmann, E.W.Kuenzi, A.J.Stamm, (1975) Principles of Wood Science and Technology - II - Wood Based Materials, Springer-Verlag Berlin, Heidelberg, New-York.

F.T.A. (2003) Thermo Wood Handbook, Finnish Thermowood Association, Helsinki.

H.Epmeier, M.Westin, A.O.Rap, T.Nilson, (2003) Comparison of Properties of Wood Modified by 8 Different Methods Durability, Mechanical and Physical Properties., In: Van Acker, J. and Hill, C. (Eds). Proceedings of the First European Conference on Wood Modification, Ghent University (RUG), Belgium.

H.Militz, (2002) Thermal treatment of wood, European processes and their background. In: International Research Group on Wood Protection, No. IRG/WP 02-40241.

L.Phuong, S.Shida, Y.Saito, (2007) Effects of heat treatment on brittleness of Styrax tonkinensis wood, Journal of Wood Sciences 53(3), pp.181-186.

M.Gaff, M.Gasparik, (2013) Shrinkage and stability of thermomechanically modified aspen wood, BioResources 8(1) pp.1136-1146. 
O.Percin, H.Peker, A.Atilgan, (2016) The effect of heat treatment on the some physical and mechanical properties of beech (Fagus orientalis Lipsky) wood, Wood Research, 61(3), pp. 443-456.

O.Unsal, U.Buyuksari, N.Ayrilmis, S.Korkut, (2009) Properties of wood and wood based materials subjected to thermal treatment under various conditions, Proceedings of the 7thInternational Conference: Wood Science and Engineering in the Third Millennium-ICWSE, $4^{\text {th }}-6^{\text {th }}$ of June, Brasov, Rumania.

R.E.Ibach, (2010) Wood handbook: Wood as an engineering material - Specialty treatments, USDA Forest Service, Forest Products Laboratory, General Technical Report FPL-GTR190, Madison, WI.
R.Kotilainen, (2000) Chemical changes in wood during heating at $150-260^{\circ} \mathrm{C}$, Väitöskirja, Jyväskylän yliopisto, Kemian laitos, Soveltava kemia, Jyväskylä.

S.Ferrari, O.Allegretti, I.Cuccui, J.Sandak, A.Sandak, (2012) Thermo-vacuum process for wood thermal modification: results for some European softwood and hardwood species treated at different conditions, The Sixth European Conference on Wood Modification, 17th-18 ${ }^{\text {th }}$ of September, Ljubljana, Slovenia.

V.Boruvka, A.Zeidler, T.Holecek, R.Dudik, (2018) Elastic and strength properties of heat-treated beech and birch wood, Forests 9(4), pp.1-18. 